\section{El pensamiento complejo como herramienta clave ante el desafío de la igualdad de los seres humanos}

Complex thought as a key tool to face the challenge of equality for human beings
Carmen Gil del Pino ${ }^{1}$

ed1gipim@uco.es

https://orcid.org/0000-0002-8062-2250

Sonia García-Segura ${ }^{1}$

sgsegura@uco.es

https://orcid.org/0000-0003-2928-3334

https://doi.org/10.22209/rhs.v8n1a04

Recibido: noviembre 12 de 2019

Aceptado: marzo 18 de 2020.

\section{R e s u m e n}

Hoy, cuando los poderosos de la tierra avanzan a la velocidad de un meteoro con el solo objetivo de mercantilizarla en su provecho -su lógica es el ganador se lo lleva todo-; cuando, necesitados de desigualdad (se nutren de interdependencia asimétrica), ahondan la brecha abierta en el mundo y distancian cada vez más a sus dos mitades -la del hambre y la de la hartura-; cuando siembran el pensamiento propio por todo el planeta y convierten el ajeno en uno de baja intensidad, en un pensamiento cero; cuando roban lo más precioso del ser humano, que es la palabra; cuando, en resumen, la globalización del Mercado nos aniquila, este artículo penetra en la senda del fenómeno, localiza sus hitos -desigualdad y lejanía entre los hombres, desalojo del pensamiento, hurto del logos $-y$, sirviéndose de ellos, construye un camino de vuelta, de ascensión: rescate de la palabra (beIla, o sea, propia), pensamiento complejo y cercanía e igualdad de todos los seres humanos.

Palabras clave: globalización; humanidad; lenguaje; logos; pensamiento cero.

\section{Abstract}

Nowadays, when the mighty of the earth advance at the speed of a meteor with the sole objective of commodifying for their own benefit-under a winnertakes-all logic-; when, in need of inequality (they are nourished by asymmetric interdependence), they deepen the gap opened in the world and increasingly distance its two halves -hunger and feast-; when they sow their own thinking all over the planet and label the alien thinking as being low intensity or zero thought; when they steal the most precious thing in every human's life, that is the word; when, in summary, the globalization of the market annihilates us, this paper addresses the phenomenon, locates its milestones -inequality and distance between men, eviction of thought, theft of logos- and through them it builds ways of return, ways of ascension: the rescue of the word

1 Universidad de Córdoba, España. 
(a beautiful word, that is, a word of one's own), the complex thought and the proximity and equality of all human beings.

Keywords: globalization; humankind; language; logos; zero thought.

\section{Introducción}

De ninguna manera se puede adormecer a una multitud sin su consentimiento. No está permitido arrebatar a la gente el juicio ni entumecer su corazón, ni aun en el caso de que, encaramada en lo alto de un artilugio que se precipita velocísimo a las más insondables profundidades, discurra sin remedio hacia su desmoronamiento, hacia la muerte segura. Nunca puede estar éticamente justificado aquietar a las masas contra su deseo (no, porque la vida es un acto de libertad: el supremo). Menos aún si los viajeros somos todos, si el artilugio es el mundo y si su trayectoria es reconducible.

Sin embargo, hoy, con el avance vertiginoso de la globalización, la ofensiva homogeneizadora más poderosa e inhumana de cuantas se han producido a lo largo de la historia, ${ }^{2}$ una ofen-

2 El catedrático de Antropología Social de la Universidad de Sevilla Isidoro Moreno, en su interesante artículo Globalización, mercado, cultura e identidad, recogido por la profesora de la UNED Paz Moreno Feliu en el libro Entre las Gracias y el Molino Satánico (485-514), describe tres intentos de globalización anteriores al de hoy, cada uno de ellos basado en una lógica específica presentada como Absoluto Social. La lógica del primero fue la religión. Apoyándose en ella, el cristianismo y el islamismo, obviamente por separado, adoptaron proyectos globalizadores y convirtieron sus respectivas doctrinas en pensamiento único. El segundo ataque globalizador consistió en el intento de imponer a todo el planeta el modelo de estado-nación con su discurso de la democracia liberal. El firme en el que se sustentó fue, como cabe suponer, siva cuyo objetivo básico es mercantilizarlo todo, los poderes (terrores) políticos (económicos), con tozudez y por la fuerza (sutil o bruta), están dictando una consigna espantosa, alarmante, una consigna cargada de corrompida significación, de intenciones abominables. No pensar y no sentir, esta es la orden pregonada por todas partes, en todo momento. Al ser humano se le está exigiendo, enérgicamente, que congele sus últimas y auténticas realidades -el razonamiento y las emociones, en total ensamblaje ${ }^{3}$, no solo para que no haga nada -las funciones cognitivas y las emotivas involucran al sujeto y lo orientan a la acción- sino también y, sobre todo, para que deje hacer. Y lo que debe dejar hacer, lo que debe permitir es que se divida el mundo (que se siga dividiendo) en dos partes asimétricas: la de los pobres -que se mueren, literalmente, de no comer-y la de los ricos - que se mueren, literalmente, de comer (tanto)-. Difícil se hace a los de una y otra parte comprender y sufrir no ya la tragedia ajena sino incluso la propia. Y es que, ante la cada vez mayor desigualdad, los detentadores del poder, interesados personalmente en ella, desactivan la cognición y el sentimiento de unos y de otros. Saben que son peligrosísimas herramientas. No se puede ya pensar, ni sentir, ni tener sueños, ni intentar que se cumplan.

la política. La tercera ola globalizadora, para Moreno, posee un fundamento ideológico y fue protagonizada por el socialismo. La actual es la cuarta arremetida globalizadora que soportamos y su razonamiento es de carácter netamente económico.

3 Para Vandamme -en Ramírez Goicoechea, E., 2005, p. 174- la emoción permite concentrar el interés, la energía, en ciertos aspectos de la realidad que, a través de los procesos simbólicos, quedarán organizados y jerarquizados. La cognición sería, pues, una metaemoción, un nivel organizativo superior por medio del que se opera en lo simbólico y se completa el proceso iniciado en el nivel de lo emocional. 
De este modo, lo que es visible y palpable (real) no llega a ser inteligible ni conmovedor. Si alguien aplica sus capacidades mentales y emotivas a, por ejemplo, el hecho de que los bienes simbólicos (educación, cultura) se compran; si piensa en el tránsito del desequilibrio económico a desequilibrio social; si repara en que el aumento de la injusticia llega a ser aumento de la desgracia, de la miseria, del riesgo, de la muerte (porque aumenta el número de personas dispuestas a jugarse la vida, personas que solo eligen entre una muerte segura y otra posible), no pasará absolutamente nada, porque su pensamiento será tan débil y su sensibilidad tan burda que no alcanzarán a informarle de la relevancia de tales realidades.

En cualquier actividad humana, ya sea física o mental, las vías que llevan al bloqueo del sujeto son fundamentalmente dos: la privación de la sustancia sobre la que opera y la privación del instrumento con el que opera. Así, en el caso de la agricultura, la alfarería o el hilado - por poner tres ejemplos sencillos-, se puede paralizar al individuo quitándole la tierra, el barro o el hilo o también quitándole la azada, el torno o el huso. Claro que en ambos casos existe la posibilidad de que busque y consiga lo que le falta. Un hombre que posea una azada siempre puede buscar y conseguir tierra de labranza y otro con canteras de barro o con abundante materia textil puede, desde luego, adquirir un torno o un huso.

Ahora bien, en el caso de las conductas cognitivas y afectivas la cosa cambia, dado que la sustancia y el instrumento son de la misma materia, y esta (sustancial e instrumental) no es otra que la palabra, el logos (el sentido, la conexión, la unidad). El mundo (interior y exterior) que se piensa y que se siente está hecho de palabras y las herramientas para pensarlo y para sentirlo (cognición y emoción) también. Es como si la azada fuera de tierra, el torno de barro y el huso de hilo. Nada podríamos hacer entonces si nos privasen de la materia elemental como tampoco hacemos nada si nos arrebatan el logos. No hay mundo para nosotros ni aparato intelectual para crearlo. Estamos aniquilados por partida doble. De ningún modo podemos vivir (en el pleno sentido de la palabra) sin lenguaje, ya que es la realidad auténtica y primaria del ser y del mundo. Sin él se paraliza nuestra razón y nuestro sentimiento y, lógicamente, nos paralizamos, nos desmoronamos nosotros. Dice, con razón, Sánchez Corral (2004, p.10), que «somos nuestro propio lenguaje (el que producimos y el que recibimos)».

Aunque resulta evidente que el hurto del logos es un proceso único e integrado, lo presentaremos, para su mejor comprensión, dividido en dos actos: el primero, con el significado como escenario, versará sobre el ataque que sufre la función de denominar, de referir, de sentar la realidad (privación, pues, de la sustancia lingüística a la que aludíamos antes, del eje vertical [en términos de Jakobson] del lenguaje); el segundo, cuyo telón de fondo va a ser el predicado, tratará del bloqueo de la función de levantarla, de moverla, de tramarla (privación ahora de la herramienta lingüística, del eje horizontal de Jakobson). 
El robo de la sustancia lingüística y la imposibilidad de nombrar el mundo (y de nombrarse)

El mundo es un caos, un enigma que solo puede organizarse y resolverse con el pensamiento asistido por el lenguaje, que es su principal medio de producción. ${ }^{4}$ «El intelecto, como hábil ingeniero que por medio de diques gana al mar terreno y lo aleja, va reduciendo el desorden a orden, el caos a cosmos» (Ortega y Gasset, 2004, p. 443), y lo hace con palabras. «Creamos realidades advirtiendo, estimulando, poniendo títulos, nombrando...», ha dicho Bruner (1987, p. 74).

Vivir, en el pleno sentido del término, es pronunciar, y pronunciar no es expresar un orbe existente, sino componer uno nuevo producto del pensamiento de cada hombre y "con una existencia en el "mundo objetivo" de la cultura» (Bruner, p. 54). No hay, pues, una realidad única anterior al acto simbólico humano sino una que se crea al decirla, y se crea simultáneamente al sujeto que la dice. Hombre y realidad serán tan ricos, extensos y profundos como rico, extenso y profundo sea el lenguaje con el que sean pronunciados.

Pues bien, cada elemento del «mundo objetivo», cada referente, puede ser expresado a través de múltiples palabras. El hablante ejecuta

4 Una característica del lenguaje humano es la constitutividad, esto es, su poder de producir realidades, de transformar los procesos cognitivos en productos dotados de alguna realidad en algún mundo, su rasgo creador, en definitiva. Jerome Bruner lo explica magníficamente en el capítulo IV de su libro Realidad mental y mundos posibles. lo que Jakobson (en Bruner, 1987, p. 33) llama el acto de selección, que es un acto a través del que elige, de la extensa gama de palabras que componen el eje vertical del lenguaje -eje que recorre toda la sinonimia y llega hasta la metáfora, que es la significación superlativa-, la que considera más adecuada para su enunciación. Dependerá de su interés por preservar o modificar el significado.

Ahora bien, lo anterior sucede solo en el terreno de la teoría. La elección real, hoy, es una elección forzosa, regida por las elites, por los medios de comunicación, por la academia, por la cultura dominante, en suma, una cultura neoliberal que, con formas de pensamiento particulares (de naturaleza económica) y una visión propia (mercantilista) del mundo, reduce al máximo el amplio abanico de códigos e interpretaciones, de significados discordantes, e impone un marco conceptual unitario; cultura que se adentra con sus modelos en los esquemas mentales del hablante, lo somete a una fuerte tensión semántica y le produce un impacto direccional poderosísimo, con capacidad suficiente para dejarlo convertido en una prótesis suya, en un mero instrumento a su servicio; cultura, en fin, que se erige en cultura de referencia, que decide qué es la realidad al tiempo que incapacita para hacerlo (o, en el mejor de los casos, debilita) a los seres que emergen -que emergemos- en ella.

$Y$ es que el sistema lingüístico no es inocuo. Las palabras condensan las metafísicas culturales. Rumano, por ejemplo, es la alternativa léxica impuesta para designar a un hombre de piel morena y manos encallecidas, generalmente extranjero mas no siempre de Rumanía, que, acorralado por una situación de injusticia, de terrible injusticia, toma a su mujer, a sus hijos, a sus hermanos, a sus padres, a cuantos 
se hallan a su cobijo, en definitiva, y, saltando todo tipo de obstáculos -cultura, idioma, economía, rechazo, clima, vivienda, sanidad, educación, etcétera-, emprende con ellos una nueva vida, una vida que en muchas ocasiones consiste en empujar como una bestia, desde que nace el sol hasta que se pone, un carro lleno de chatarra. Sin duda, un hombre arrojado, bien constituido en lo emocional, pues soporta de pie, con entereza, un doloroso y doble proceso de desaparición -en su país, del que desaparece real, literalmente, y en el de «acogida», donde lo hace metafóricamente, al no ser visto ni tenido en cuenta por (casi) nadie-; un hombre que, a fuerza de imaginación y de arrojo, se resiste a perecer; un sujeto empecinado, recio, paciente, optimista..., que realiza, en suma, de manera humilde y a la vez grandiosa, la tarea básica de la vida, que es vivir.

La palabra prostituta constituye otro nítido caso ejemplar. Nos hallamos ahora ante el término designado para hacer alusión a una mujer equivocada, pobre y soñadora, impaciente por salir de su estrechez de vida, una mujer que se engaña pensando que la miseria puede transformarse de la noche a la mañana, como se transforma en el cine, en lujo y en riqueza. Su mirada miope es, sin duda, fruto de su desigual acceso a la educación, de su batacazo académico que se muda ahora, como suele suceder, en fracaso social, en melodrama. Una mujer de fantasía extraordinaria que, armada simplemente con una barra de labios, una minifalda y unos tacones, sale noche tras noche a la calle con el respetable objetivo de realizar sus sueños. No sabe, porque nadie se lo enseñó -ni su madre, ni su padre (al que ni siquiera conoce), ni sus maestros (que enseñaban solo para la escuela, no para la vida)-, que, aunque conseguirá un mayor ingreso económico que las demás mujeres de su misma clase, no tendrá independencia ni derechos laborales; tampoco sabe, pues tampoco se lo dijeron, que el estigma asociado al medio de subsistencia que «elige» la hace absolutamente vulnerable. Está convencida de que su vida es una película y ella la auténtica Pretty woman.

Pues bien, las palabras rumano y prostituta (y tantas otras [no podemos tirar la raya y hacer la suma solo con los dos sumandos anteriores: la cuenta, tristemente, es más larga]) son abstracciones estáticas no conectadas a sus referentes, vocablos dislocados que no designan a personas reales, que no se refieren a un hombre y a una mujer de carne y hueso. Son signos exentos del mínimo de realidad que exige el simbolismo y cuyo propósito (perverso) es falsear las cosas y crear entes abstractos alejados (geográfica [en el primer caso] y moralmente [en el segundo]), no-personas, categorías sociales. ${ }^{5}$ Muchos rumanos no son rumanos sino búlgaros, rusos, húngaros, italianos o españoles, y muchas prostitutas, muchas mujeres malas solo son niñas buenas con la cabeza llena de pájaros, niñas vilmente engañadas, hechas mujeres (decentes, desde luego) en dos días a fuerza de duros y execrables golpes, niñas atrapadas en un denso bosque en el que se mezclan clase social, edad, etnia, educación y fortuna. Rumano (pobre, en

5 Del mismo modo que el fenómeno social de la esclavitud acabó en EE.Uu., la inmigración y la prostitución pueden acabar como hechos sociales, pero es muy probable que permanezcan mucho tiempo como hechos mentales, lo mismo que permanecieron las clasificaciones cognitivas, los clichés (y las consiguientes actitudes larvadas de rechazo) que acompañaron al referido fenómeno estadounidense: «Dijeran lo que dijeran las enmiendas constitucionales, la oposición cultural entre esclavo y ciudadano había quedado indeleblemente marcada en la raza y engastada en la cultura americana» (Urciolli, 2004, p. 109). 
realidad) significa hoy, rotundamente, sujeto peligroso, vago, sucio; y prostituta (también pobre, pero más impaciente que el rumano, más ilusa), mujer desvergonzada, inmoral, puta.

Si tuviésemos a nuestra disposición, desplegado tan largo como es, tan bello, el catálogo de términos existente (los sustantivos, la sustancia sobre la que trabajar), si nos estuviese permitido recorrer de arriba abajo el eje vertical del lenguaje, el que dijimos que iba desde la sinonimia hasta la metáfora, las palabras que hemos entresacado como casos ejemplares podrían ser sustituida por otras. Así, en lugar de rumano podríamos decir buscavidas, aventurero, emprendedor, desposeído, víctima, viajero, héroe, idealista, luchador, Quijote, etcétera, y en vez de prostituta quizás dijéramos joven, ilusa, desgraciada, camarera, bailarina, romántica, infeliz o soñadora.

En uno y otro caso, en todos los demás, los términos elegidos por cada uno de nosotros dependerían de nuestros actos perceptivos, cognitivos y emocionales, actos, sin duda, genuinos, pues están enlazados a las experiencias, que, obviamente, son únicas. Y si a la variedad de actos interiores sigue la terminológica, la expresión auténtica, creativa, del ser humano, tras esta se produce, se produciría, la riqueza de acciones, o sea, la libertad. En cambio $-y$ esto es lo que está sucediendo-, si la gama de palabras se comprime, si se estruja hasta dejarla reducida a la unidad, el término que resulta, el predeterminado y obligatorio, el único disponible, produce efectos tanto hacia atrás (hablamos en sentido figurado, siguiendo la secuencia lineal anterior: actos interiores, actos de habla y conductas observables), es decir, hacia el pensamiento, que, en soldadura (siempre) con el sentimiento, se vuelve «pensamiento de baja intensidad, único (o "pensamiento cero», en palabras de Enmanuel Todd» (Moreno, 2004, p. 499), como hacia adelante, o sea, hacia la acción, que se inhibe. $Y$ entonces, con el término único como único patrimonio lingüístico (existencial), ni pensamos ni hacemos. No podemos meditar («las palabras son huecos para los pensamientos», dice Ortega y Gasset [2004, p. 144]) ni intervenir en el mundo con tan insignificante cosa. Tampoco hablamos, pues solo un léxico rico puede arrancar nuestros innumerables secretos y los del orbe. Lo que hacemos es recitar, reproducir mecánicamente, interminablemente, el término disponible, la narrativa tan pobre que nos prescriben. Pero eso no es hablar, porque solo se habla, en el pleno sentido de la palabra, con el interior. $Y$ si no realizamos las funciones humanas -pensar/sentir, actuar en el mundo, hablar-, las que nos son propias, las que conquistamos en nuestro larguísimo proceso de hominización, llegamos a ser sujetos vacíos, y con nosotros el mundo, que no es otra cosa que nuestra proyección:

Las cosas son proyecciones de nuestra intimidad. Lo que anda vagando por los fondos de nuestro corazón -prosigue-, eso andará viviendo a la luz del día. Mas si tenemos el alma vacía de sustancia, si nuestro ánimo carece de contenido, ¿qué proyectaremos, qué mundo será el que pongamos ante nosotros? (Ortega y Gasset, 2004, p. 205).

En el nuevo capitalismo, sistema que nos subyuga, que nos corroe el alma, que nos sepulta..., las palabras están, dado que somos lenguaje (ya lo advertimos antes), sometidas, es decir, «se insertan en ámbitos semánticos que no les son propios, en ámbitos que incluso las repelen» (Sánchez Corral, 2004, p. 23) y prestan al amo un magnífico servicio. Por 
desgracia se está produciendo una lejanía entre significar y hablar (palabrear), lejanía que revela dos cosas, terribles ambas: o bien que hay vacío detrás de los términos, que estos son vocablos huecos, cascarones, palabrería que no significa nada, que refleja (y a la par crea) realidades aparentes (¿qué significa hoy, por ejemplo, el término hombre?, ¿es el ser animado racional que dice el DRAE [Diccionario de la Real Academia Española] o un sujeto huero?; ¿y humanidad?, ¿qué significa humanidad?; ¿y vida?; ¿y amor?); ${ }^{6}$ o bien que sobre la denotación cae una gigantesca ola de connotaciones -generalmente de naturaleza moral-, una ráfaga de sentidos novedosos, una sobrecodificación, en suma, que aniquila los marcos conceptuales previos de las personas que las utilizan en sus flujos comunicativos (como oyentes o como hablantes) y las obliga a incorporar otros generados en la cultura.

El resultado de esta operación, de este primer acto - primer hurto- del que nos estamos ocupando en el presente epígrafe -el secuestro de la significación, ${ }^{7}$ en palabras del profesor

6 Existen muchas palabras vacías, muchos moldes sin su sustancia dentro, vocablos que solo son fachada, auténticos engañabobos. "Como afirma Banedetti (1995), nunca como en este último decenio se usaron tantas palabras profundas para expresar tanta frivolidad. Conceptos como libertad, democracia, soberanía, derechos humanos, solidaridad, patria y hasta Dios se han vuelto tan livianos como el carnaval, el aperitivo, el videoclip, los crucigramas y el horóscopo». (Pérez Gómez, 1998, p. 116).

7 El lector que desee conocer bien este fenómeno puede acudir al trabajo del profesor Luis Sánchez Corral De la crisis de la significación o las palabras pervertidas, clarividente, profundo y vasto análisis del sometimiento del lenguaje (y del ser humano) que concluye, como concluyen los trabajos buenos, con un texto de gran fuerza elocutiva; escueto y sencillo pero contundente; un texto abierto que invita (empuja) al lector a dar una contestación. Es este: «Nuestra tarea [...] como educadores es evitar que esto suceda; es
Sánchez Corral (2004, p. 22)- es la pérdida no solo de formas de saber sino también de formas de sentir, de lo que se deriva, lógicamente, la pérdida de formas de hacer. Con el pensamiento y el sentimiento encadenados, sin actos intelectuales ni emotivos, concluye la acción y concluye el hombre.

Y es que, bajo la «lógica» imperante, una lógica mercantilista cuya regla capital es yo me lo llevo todo, los términos cumplen, por encima de su función referencial, una de naturaleza ideológica, la que le asignan a toda hora, en cada minuto, los misioneros del Mercado, incansables en su tarea de producir desigualdad, pues el gigante insaciable que los rige se alimenta de interdependencia asimétrica. Nos referimos a la función de valorar, jerarquizar, categorizar o discriminar. El profesor Gimeno Sacristán (2002, p. 54) lo explica magníficamente:

Al asignar los nombres con los que distinguimos a los individuos también los jerarquizamos (es la diversidad valorada). Ser diferenciado y visto como listo, subnormal, negro, gitano, o ser calificado como sobresaliente en matemáticas, es ser descrito a la vez que valorado y jerarquizado

evitar que la crisis de la significación deteriore nuestra práctica». ¡Setenta páginas de intenso análisis y un recordatorio de apenas tres líneas para concluir! ¿No es esto una bien urdida estrategia de filólogo, de dialéctico, para movernos? ¿No se halla la brevedad, la sencillez última en compenetración con la amplitud y hondura anterior? ¿No va buscando algo el finísimo analista con el contraste? Presumimos que sí. Decirnos sin florituras que nuestro oficio es impedir el terrible mal que antes ha explicado largamente es zarandearnos para que reaccionemos. Y tendremos que hacerlo. Tendremos que cumplir nuestra obligación. De lo contrario, «más vale que [...] ahondemos bien en la tierra, nos tendamos en el hueco, cerremos los ojos y preparemos nuestra postura para la eternidad» (Ortega y Gasset, 2004, p. 213). 
respecto a los demás. Además de haber inventado palabras para denominar las diferencias, las acompañamos de valoraciones a las categorías de sujetos que ellas representan.

Así las cosas, se hace absolutamente preciso, urgente, liberar las palabras, que han sido -están siendo- arrancadas con violencia (sutil, simbólica) de su sentido originario y transportadas contra la lógica y contra la ética a uno inadecuado y malévolo. Ello supondrá desatender la imagen (seudo) objetiva a la que nos remiten los términos perversamente marcados e introducidos en nosotros a martillazos y poner toda nuestra atención en la subjetiva, la racional y sensible, la imagen que nuestros ojos limpios nos vuelcan dentro, la que penetra en nuestra conciencia y se transforma en parte de nosotros mismos. "El lenguaje, si se trata de lenguaje propio en lugar de ajeno, merece la pena», nos advierte ahora Sánchez (2004, p. 11) con el deseo de infundirnos ánimo. Todavía somos legión los que creemos que «este mundo, con todas sus contradicciones, aún puede salvarse, aún puede renacer» (Du Bois, en Chomsky, 2003, p. 7). Retomaremos esta idea tras desenvolver el epígrafe siguiente.

\section{La usurpación del derecho de describir, interpretar y transformar el mundo: conocimiento en mosaico} y pensamiento discreto

Tenemos capacidad para expresar un número infinito de frases, frases nuevas, encima, frases que no han sido enunciadas nunca antes. Podemos decir, por ejemplo, la oruga rabiaba por ser mariposa, se volvió el río justo al llegar al montoncito de arena, o la margarita abrió sus labios y se bebió de un sorbo la blanda gota de rocío. Es muy probable que lo anterior, así, tal como aparece, no lo haya pronunciado nunca nadie. Podemos hacer, desde luego, miles de combinaciones con las unidades lingüísticas, porque poseemos un lenguaje dotado de reglas generales (subyacentes a todas las lenguas) y particulares (propias de cada lengua), un sistema lingüístico interiorizado cuyo cometido es modelar y transformar la experiencia:

El lenguaje proporciona [...] un medio no solo para representar la experiencia sino también para transformarla. Como Chomsky (1957) y Miller (1962) han puesto de manifiesto en los últimos años, las reglas transformacionales de la gramática suministran un instrumento sintáctico para reordenar las realidades que uno experimenta. No solo decimos que el perro mordió al hombre sino también que el hombre fue mordido por el perro, o tal vez que el hombre no fue mordido por el perro, o incluso nos preguntamos si el hombre fue o no mordido por el perro. (Bruner, 1988, p. 50)

Si antes nos hemos referido al eje vertical del lenguaje - según Jakobson- y al acto primitivo de selección, nos estamos refiriendo ahora al eje horizontal y al acto de combinación, «inherente al poder generativo de la sintaxis para combinar palabras y frases» (Bruner, 1987, p. 34), para predicar, para describir y cualificar. 
$\mathrm{Y}$ es que el lenguaje humano ${ }^{8}$ se caracteriza por ser un lenguaje de doble articulación, es decir, un lenguaje que implica «una correspondencia fonético/semántica entre las palabras entendidas como sonidos y [...] como significados» (Cela Conde y Ayala, 2005, p. 492). Nuestro lenguaje requiere, por tanto, dos pasos: el primero consiste en transformar las series de sonidos simples (consonantes y vocales) en palabras; el segundo, en convertir las series de palabras en frases, en infinitas frases. Se trata, en consecuencia, de un lenguaje creador, puesto que nos permite generar, a todos, multitud de enunciados predicativos. "Cualquier persona (casi a cualquier edad) puede contar una historia [...] Pero la gran ficción [...] requiere que las intuiciones se transformen en expresiones de un sistema simbólico» (Bruner, 1987, p. 27).

Pues bien, la paradoja ahora es más llamativa, más grave. Si en el epígrafe anterior veíamos cómo se nos imponen los términos y su significación, cómo los sujetos (vacíos o estigmatizados) de nuestras (hipotéticas) oraciones nos vienen dados, si veíamos cómo se nos impide realizar libremente, felizmente, el acto

8 Los animales también tienen lenguaje; es decir, se comunican. Lingüistas, filósofos, psicólogos, etólogos, primatólogos, etcétera, han dedicado mucho tiempo y esfuerzo a dilucidar si el lenguaje es un rasgo distintivo de nuestra especie o si está presente también en otros animales próximos a nosotros (como el chimpancé), más alejados (como las ballenas) o incluso muy remotos (como las abejas). Existen abundantes argumentos tanto en un sentido como en otro. Parece ser admitido por todos, no obstante, que el animal no puede adquirir una competencia lingüística como la nuestra, aunque sí posee sistemas propios de comunicación. Los monos verdes, por ejemplo, emiten señales de alarma distintas -en un trabajo de campo, Cheney y Seyfarth (1981, en Cela Conde y Ayala, 2005, p. 490) encontraron cuatro- según los predadores que los acechan. de la selección, cómo se nos arrebata, en resumen, la sustancia lingüística, ahora llegamos a la cima del destrozo, a la apoteosis, al segundo y último acto, un acto sucio que tiene el predicado como escenario y que consiste en el robo de la herramienta lingüística, el instrumento con el que podríamos tramar la realidad (el que comparábamos en nuestro ejemplo primero con la azada, el torno y el huso). Se nos impide así tejer los hilos que vemos entre los significados (hasta que, de pura quietud, dejamos de verlos), expresar relaciones nuevas, enunciar predicados independientes; se nos prohíbe, en definitiva, ejecutar el acto de la combinación, o lo que es lo mismo, desplazarnos por el eje horizontal. A cambio, se nos entrega, también a martillo, como se nos entregaron los significados perversos, el guion de la historia, un solo guion para escribir (copiar) una sola historia, que resulta ser la historia de nuestra (prescrita) vida. En consecuencia, el lenguaje creador se torna lenguaje ritual, texto que responde a modelos claramente especificados en el que no cabe el accidente, enunciado regido por algoritmos exactos de ejecución con cero grados de libertad, precepto, liturgia. Ningún ámbito de la vida escapa ya al sistema cerrado de opciones, a la predeterminación absoluta que impone la gran narrativa. Todo está bajo control.

Así, la escuela, narradora infatigable, repite la misma monótona y farragosa copla, el mismo monótono y farragoso sermón («la clase, como hecho de habla, dice Frederick Erikson [1993, p. 337], se sitúa a mitad de camino entre la misa católica y el sermón evangélico»» ),

9 En la misa católica, los actos de habla están altamente ritualizados; en ella todo se establece de antemano: los turnos de palabra del sacerdote y de los feligreses, los textos que uno y otro pronuncian, las acciones no verbales que ejecutan y hasta la entonación de lo que 
copla o sermón, monserga, si se quiere, que le han confiado los peones de la economía global -como un honor, para colmo- con el encargo de que la repita hasta la saciedad, de que haga con ella pomposas disertaciones en las que, como observa con clarividencia Freire (1993, pp. 75-76), «la palabra se vacía de la dimensión concreta que debería poseer y se transforma en una palabra hueca, en verbalismo alienado y alienante». Nada más penoso.

Pero aún hay más, porque es preciso decir que la erudición barata inscrita y prescrita en los sacros libros de texto, la doctrina cristalizada en ellos, transforma a los educandos, como también advierte el pedagogo de la esperanza (Freire, 1999, p. 76), en «vasijas», en recipientes que son «llenados» por el educador para que, una vez llenos, una vez bien memorizada la cantinela (nada pretende con tanto afán este tipo de educación, a la que Freire llama educación bancaria, como que los educandos memoricen el contenido narrado), la repitan mecánicamente, sin sentido, sin logos (i-lógica), una y mil veces.

Cosa parecida puede decirse del ámbito del trabajo, en el que las palabras fenecen de asfixia, de rigidez, de hastío ${ }^{10}$. Aquí el lengua-

dicen. Por su parte, el diálogo entre un pastor evangélico y los fieles durante el sermón se organiza de una forma algo más libre: "no existen turnos preestablecidos, el contenido [...] del ministro no está totalmente determinado [...]; aunque las posibilidades de respuesta (de los fieles) [...] son más limitadas que las del ministro» (Erikson, 1993, p. 336).

10 En muchos trabajos apenas se habla. Piénsese, por ejemplo, en un guardajurado que vigila de pie y solo a la entrada de un centro comercial durante interminables horas de interminables jornadas; o en una charcutera, obligada a decir mil veces al día la serie ¿qué le pongo?, otra cosita, muchas gracias, en cuyo monótono texto solo existe una variación: el número con el que llama a sus inagotables clientes. je es también, como en la escuela, como en todas partes, puramente instrumental. La herramienta básica de cualquier empresa no es precisamente el logos sino la máquina, una máquina «inteligente» cuyo ronroneo diluye el habla de sus usuarios, que se vuelven puros objetos económicos desprovistos de la comprensión de lo que hacen. ${ }^{11}$ «El ser humano va adquiriendo cada vez más las características de una "cosa" y como tal cosa cobra sentido en función de su utilización» (Marquina Espinosa, 2004, p. 476).

Y si nos adentramos, por robustecer un poco más la idea, en el territorio lingüístico de la vida social, si examinamos el lenguaje común y espontáneo, el de la casa y el de la calle, el íntimo, descubriremos bien pronto que nos hallamos bajo la guía de numerosísimos patrones narrativos, de infinidad de textos culturales que se han apoderado de nuestra mente y de nuestra lengua, textos que dominan nuestros razonamientos y nuestras expresiones lingüísticas, que constituyen, en fin, el fondo organizador de todas las combinaciones posibles. Refranes, fórmulas de cortesía, sentencias morales, fábulas, cuentos, mitos, etcétera, conforman una herencia lingüística secular que nos traspasa íntegramente, una provisión de argumentos que nos presiona y moldea, un fuego vivo, en fin, que nos forja. ${ }^{12}$

11 Personas que aprietan botones, que miran pantallas, que ponen sellos..., que realizan, en definitiva, trabajos simples, se vuelven, lógicamente, simples. «Cuando las cosas nos resultan fáciles [...], ha dicho el sociólogo y profesor Richard Sennet (2000, p. 77), nos volvemos débiles; nuestro compromiso con el trabajo se vuelve superficial, pues nos falta la comprensión de lo que estamos haciendo».

12 No habrá quien ponga en duda que buena parte del lenguaje que producimos o recogemos a diario se compone de expresiones hechas en nuestra cultura, que «hablamos» sobre un cúmulo de frases bien 
Falta por traer a escena, para acabar de componer (descoyuntar) el panorama, para cerrar este segundo ataque al pensar y al decir propios, al crear, un apunte que en modo alguno carece de importancia, y es que los predicados que proferimos no solo son textos ajenos -textos que, consiguientemente nos enajenan- sino también textos fragmentados que, asimismo, nos fragmentan. En tales circunstancias, alienados y rotos, no podemos comprender las situaciones en las que estamos inmersos, ni las injusticias que soportamos, ni los derechos que tenemos. Tan solo podemos explicarnos mágicamente -no de modo crítico- las situaciones, adaptarnos al mundo -no cambiarlo-, reproducir -no crear-, tener pesadillas -no sueños-. Dicho con mayor concisión: no podemos ser, porque muerta nuestra capacidad reflexiva y crítica -que muere-, muerto nuestro espíritu, quedamos incrustados en el orden de las realidades utilitarias, en el orden de las cosas.

En resumidas cuentas, que las enunciaciones que se nos inyectan en vena al menor descuido -en el trabajo, en los medios de

tramado que, al menor descuido, se nos cuela por la boca y sale enseguida dando a entender que procede de nuestra alma (lo que, al tercer o cuarto ensayo, no más, acaba sucediendo). Emitimos muchos textos no pensados, textos de los que solo somos conscientes si, por error, se produce alguna variación en ellos (muchos de nosotros nos habremos sorprendido diciendo buenos días por la tarde, o me alegro de verte a alguien que se halla en una situación desafortunada), textos que casi nunca son inocuos. Refranes como dime con quien andas y te diré quien eres, cada oveja con su pareja, Dios los cría y ellos se juntan, cuando el río suena agua lleva...; dichos como siempre ha habido clases, así es la vida, las cosas son como son, trabajas como un negro, pareces un gitano...; relatos, en fin, como el de la manzana podrida o tantísimos otros no son, desde luego, inocentes. Cumplen una bien urdida función: la de ahondar la brecha entre la mitad que muere de hambre y la que lo hace de hartura. comunicación, en la escuela, en la calle...- y que seguidamente exhalamos nosotros, no solo están sometidas sino también desarticuladas. Son enunciaciones en mosaico, discretas, inconexas (y «la inconexión, dice Ortega [2004, p. 749], es el aniquilamiento»), enunciaciones que constituyen un collage, un tendedero de información que satura y descoyunta nuestra mente y la incapacita para la comprensión coherente del mundo:

Esta desarticulación del conocimiento conlleva la anestesia de la conciencia, sin la cual es imposible desarrollar una postura política clara. Tal como ha indicado elocuentemente Frei Betto, la percepción clara de la realidad requiere que cada cual transcienda «la concepción de la vida como un simple proceso biológico para llegar a entenderla como un proceso personal y colectivo». Betto se refirió a esa concepción errónea como «el tendedero de la información»; puede haber colgada en él una gran cantidad de piezas de información, pero no todo el mundo es capaz de relacionarlas unas con otras. (Macedo, en Chomsky, 2003, p. 17)

\section{El camino de vuelta. hacia el pensamiento complejo por la metáfora y la creación}

Si del primer ataque, el que denominamos El hurto de la sustancia lingüística y describimos en el apartado uno, salimos vacíos -como una parte de nuestro vocabulario- y pervertidos como otra-, del segundo, del que acabamos de ver bajo el nombre de La usurpación del derecho de describir, interpretar y transformar el mundo, un ataque en el que se nos priva del 
lenguaje como instrumento (en su función de significar, de mover la realidad), de esta segunda arremetida, decimos, resultamos peor parados aún, maltrechos ya del todo, porque quedamos, ya lo hemos dicho, alienados y rotos. Si primero, a fuerza de palabras huecas y pervertidas, se nos vacía y pervierte, luego, a fuerza de textos ajenos y troceados, se nos llena con otro ser (con el opresor, dice Freire ${ }^{13}$, que nos invade, que nos suplanta, que se nos aloja dentro) y se nos trocea. Nos dejan, pues, como nos quieren, como nos necesitan: vacíos, pervertidos, alienados y rotos, cual humo que ni siquiera puede subir, humo quieto, porque, recordémoslo, nos hallamos en un punto, precisamente en el que se cruzan los ejes vertical y horizontal del lenguaje, ejes que, como hemos visto, no nos permiten recorrer. $Y$ del mundo, que es nuestra proyección, puede decirse justamente lo mismo. ¿No vamos a remediarlo?

Si no lo hacemos, si permitimos que se consume el robo del lenguaje, si consentimos que concluya el proceso pensamiento débil, pensamiento único, pensamiento cero, estaremos en condiciones de iniciar el regreso al momento exacto, remotísimo (hace aproximadamente diez millones de años $\left.{ }^{14}\right)$, en el que

13 «Los oprimidos, como seres duales, inauténticos, [...] “alojan” al opresor en sí» (Freire, 1983, p. 41).

14 Todos los seres vivos descendemos de antepasados comunes y nos vamos diferenciamos de ellos a medida que transcurre el tiempo. Así, nuestros antecesores de hace diez millones de años, según el antropólogo Camilo José Cela Conde y el biólogo Francisco J. Ayala (2005, pp. 15-16), eran unos primates con una morfología parecida a la de un chimpancé o un gorila; los de hace cien millones eran pequeños mamíferos semejantes a una rata o una ardilla; y los de hace cuatrocientos millones de años eran unos peces. «De tal forma, los humanos y los chimpancés descienden de un antepasado común que vivió hace menos de 10 millones de años, mientras que, para nos separamos de los chimpancés. Acabaremos disponiendo solo, como disponen ellos, de un repertorio de señales con un contenido semántico muy preciso, señales siempre discretas y jamás relacionadas con emociones, de las que, por otra parte, no nos quedará ni la más primitiva, que es, en palabras de Ortega (2004, p. 442), «el espanto, el miedo a la realidad». Esta nos va a ser, nos está siendo ya, del todo indiferente.

La conducta simbólica, conseguida por nuestra especie en un larguísimo período de tiempo, ${ }^{15}$ está hoy en serio peligro. El pensamiento, cada vez más lejos del conocimiento -terrible paradoja- está a punto de ser derrocado. Del peligro que corremos si se produjese la escisión definitiva de estos nos avisa Hanna Arendt (en Tedesco, 1995, p. 24): «Si sucediera que conocimiento [...] y pensamiento se separasen definitivamente -dice- nos convertiríamos en impotentes esclavos no tanto de nuestras máquinas como de nuestros know-how, irreflexivas criaturas a merced de cualquier artefacto técnicamente posible, por muy mortífero que fuera».

Nos hallamos, pues, en una situación muy delicada, en un momento terrible. Zarandeados por mecanismos y repertorios que, en ciclón,

encontrar el último antepasado común de los humanos, los gatos y los elefantes hay que remontarse a hace más de 50 millones de años».

15 La tesis gradualista, defendida por las investigadoras McBrearty y Brooks (2000, en Cela Conde, C.J. y Ayala, F.J., 2005, pp. 478-450), constituye, a nuestro juicio, la postura más razonable para entender el origen del simbolismo humano. Las referidas científicas rebaten con argumentos de peso la idea mayoritariamente aceptada de una «revolución cognitiva», de un cambio mental brusco acaecido con la aparición de los humanos de aspecto moderno. 
vienen de fuera, estamos a un paso de convertirnos en hombres-máquina. Nuestra voluntad se vuelve estática, y no podemos, sin ella, construirnos. Dice en sus memorias don Gaspar de Mestanza que, si se le preguntara por el cambio más grave presenciado por él, si tuviera que señalar el síntoma más terrible de su época ${ }_{1}^{16}$ no vacilaría en dirigir su dedo hacia el fabuloso acortamiento del «radio de individualización» acaecido en el siglo XX (en Ortega y Gasset, 1955, pp. 135-140), y este no es para él otra cosa que la holgura para ser persona. De vivir ahora, Mestanza podría comprobar que la reducción ha proseguido, que prosigue aún. Y si, como dijo, dicho radio es la magnitud decisiva para juzgar una época, la nuestra será juzgada, sin duda, por el triste mérito de casi alcanzar ya el punto cero.

Íbamos, al empezar este artículo, subidos en un artefacto -el mundo- que se precipitaba al vacío con la velocidad de un meteoro. Dijimos allí mismo que su trayectoria era reconducible. Así lo creemos todavía, pese a la desnudez fea que el duro análisis nos ha mostrado de las cosas. Lo creeremos siempre. Estamos convencidos de que los acontecimientos no solo pueden tomar otro rumbo, sino que lo van a hacer. Los seres humanos, ocupantes del artefacto que se precipita velocísimo al vacío, tenemos capacidad y motivo suficientes para reorientar su rumbo, o lo que es lo mismo, para recuperar lo que es nuestro: la palabra.

Ciertamente, estamos capacitados por naturaleza para frenar el flujo en masa de términos y textos instrumentales, textos regidos por reglas y estrategias extrañas, ligados a intereses técnicos, mercantiles..., y para producir los propios, los regidos por reglas y estrategias

16 Nació en 1855 y murió de ochenta años. comprendidas y sentidas, textos ligados a intereses prácticos, humanos. Estamos biológicamente capacitados para desencadenar significaciones múltiples y para combinar. $Y$ es que nuestro pensamiento, complejo (no discreto), adquirió en su desarrollo lo que los científicos denominan crossmodalidad, que es una disposición a establecer vínculos entre elementos cognitivos y a trasvasarlos de un dominio a otro. Enlazando la idea con la argumentación que traemos, podríamos decir que es la capacidad de unir conceptos, -de emplear, por tanto, la sinonimia y la metáfora- y de combinar predicados -de crear-, o si queremos, de deslizarnos por los ejes vertical y horizontal del lenguaje. La profesora de Antropología Social de la UNED Ramírez Goicoechea (2005, pp. 150-151) explica la crossmodalidad del siguiente modo:

El rol de la metáfora ha sido de particular interés para los antropólogos sociales. Vico ya mencionó nuestra limitada capacidad para la especialización y, sin embargo, tenemos una [...] casi ilimitada para combinar elementos viejos en contextos nuevos (cf. Fernández, 1991). La crossmodalidad es una de las fuentes principales de creatividad e innovación. Por ejemplo, las metarreglas, reglas de reglas, son principios generales originados en un dominio, pero aplicados a otro, constituyendo referencias de orden superior. La complejidad de la vida no permite elaborar reglas para cada dominio, por lo que las metarreglas se generalizan para dominios específicos. [...] La crossmodalidad está en la base de nuestra capacidad simbólica y presupone un incremento de la conectividad de sistemas y sistemas de sistemas neuronales. ${ }^{17}$

17 Las cursivas no son originales. 
Poseemos, pues, una arquitectura mental blanda, flexible. Nuestro cerebro es apto para el juego, para el gozo del lenguaje. Puede hacer que las palabras rumano y prostituta, nuestros casos ejemplares, rompan sus rígidos caparazones, entren en erupción y se hagan actividad nuestra, materia interna en estado fundente ávida de una nueva forma. ${ }^{18}$ Nuestro cerebro puede aniquilar todas las cosas y dotarlas de un nuevo cuerpo; puede extraerlas de sus moldes y hacerlas fluir hacia otros ideales, bellos; puede lograr, en fin, la compenetración perfecta entre conceptos. Pero la crossmodalidad no se activa automáticamente, sino que es propiciada -o inhibida- por el individuo y por la cultura. Ya hemos visto que esta, verdadero tejido de significados, como afirma Geertz (1993, en Pérez Gómez, 1998, p. 15), la está paralizando hoy día, pero el individuo puede moverla de nuevo -él es quien hace la cultura-, y puede moverla a través del arte, concretamente del arte de la palabra (esta es nuestra tesis), que, al poner en juego simultáneamente pensamiento y sentimiento, 0 , si se quiere, lógica, ética y estética, primero desorganiza la realidad que es y, a continuación, organiza la que debe ser, bellamente, además, «Cuando el hombre organiza racionalmente dice Castoriadis (1993, en Pérez Gómez, 1998, p. 15) - no hace más que reproducir, repetir o prolongar formas ya existentes. Pero cuando organiza poéticamente, da forma al caos». Desrealizar el mundo y realizar otro más bello y mejor es el oficio, pues, del poeta. Aristóteles, en El arte poética (1970, p. 45), lo expresa en estos términos:

18 Remitimos al lector, para que goce como lo hemos hecho nosotros, a La metáfora, un magnífico texto del filósofo Ortega y Gasset que aparece en el libro que venimos manejando Obras Completas, Tomo I, páginas 672-677.
No es oficio del poeta el contar las cosas como sucedieron, sino como debieran o pudieran haber sucedido, probable o necesariamente; porque el historiador y el poeta no son diferentes por hablar en verso o en prosa (pues se podrían poner en verso las cosas referidas por Herodoto, y no menos sería la verdadera historia en verso que sin verso); sino que la diversidad consiste en que aquél cuenta las cosas tales cuales sucedieron, y éste como era natural que sucediesen. Que por eso la poesía es más filosófica y doctrinal que la historia.

Y de la misma manera que poseemos capacidad para rehacer metafóricamente, creativamente, la cultura, también poseemos motivo para hacerlo, un motivo doble, además: el deber y el placer. Por lo que atañe a la primera razón, no puede quedarse sin decir que, en este reino bimembre -recordemos: la mitad del hambre y la de la hartura-, un reino en el que los comisarios culturales cumplen magníficamente su cometido - «mantenernos apartados de las cuestiones reales y apartados a unos de otros» (Chomsky, 2003, p. 33)-, nosotros, es decir, políticos, filósofos, educadores, filólogos, economistas, sociólogos, ciudadanos con conciencia, en suma, habremos de cumplir el nuestro: unir. Ni aun siendo cosas podemos permanecer en aislamiento, porque hasta estas cobran sentido solo cuando entran en relación con las demás:

¡Cuán poca cosa sería una cosa si fuera solo lo que es en el aislamiento! ¡Qué pobre, qué yerma, qué borrosa! Diríase que hay en cada una cierta secreta potencialidad de ser mucho más, la cual se liberta y expansiona cuando otra u otras entra en relación con ella [...]. El «sentido» de una cosa es la forma suprema de su 
coexistencia con las demás, es su dimensión de profundidad. [...] Platón ve en el «eros» un ímpetu que lleva a enlazar las cosas entre sí; es -dice- una fuerza unitiva y es la pasión de la síntesis. (Ortega y Gasset, 2004, p. 782)

Pero como no nos vamos a conformar con ser cosas religadas, sino que aspiramos a ser lo que nos corresponde, es decir, personas singulares; como aspiramos a desplegar el proyecto de nosotros mismo (nuestra existencia) $y$, por tanto, a conformar nuestra entidad (que es la fusión de esencia [o quididad] y existencia [o perfección]), tenemos ahora que acudir a la pedagogía, cuya tarea es, precisamente, lograr lo anterior, es decir, crear seres únicos, y los seres únicos piensan y dicen cosas únicas, las cosas que ven solo ellos, el mundo que se extiende ante su retina, un mundo que han de materializar con palabras para insertarlo en el objetivo, que se compone de los infinitos mundos posibles.

La segunda razón era el placer. Si hay algún gozo mayor que decir bellamente el pensamiento y el sentimiento y apreciar cómo estos, al dulce fluir de las palabras, se ensanchan y embellecen; si algo satisface más a un alma que pintar con palabras hermosas el mundo ideal con el que sueña y advertir que toma cuerpo, que se hace concreto, el más concreto y verdadero de todos los mundos; si alguna cosa es más placentera que descubrir que «no hay [...] ningún significado en el ser [...]; (que) nosotros creamos el significado sobre un fondo sin fondo, [...] (que) damos forma al caos mediante nuestro pensamiento, nuestra acción, nuestro trabajo, nuestras obras» (Castoriadis, 1993, en Pérez Gómez, 1998, p. 44); si hay algo -concretamos ya- que provoque más deleite en un corazón que crear un texto bello (que resulta ser un mundo bello en el que nos zambullimos, bellos nosotros también, pues nos hacemos al producirlo), alguien debería declararlo y argüirlo. De lo contrario, será la creación poética el disfrute supremo. Esta es, resumida, nuestra tesis: no hay más modo de salvarse que hablando (bellamente), y tenemos la disposición y las razones para hacerlo. Solo nos falta la voluntad.

\section{REFERENCIAS}

- Aristóteles. (1970). El arte poética. Madrid: Espasa Calpe.

- Bruner, J. (1987). Realidad mental y mundos posibles. Los actos de la imaginación que dan sentido a la experiencia. Barcelona: Gedisa.

- Bruner, J. (1988). Desarrollo cognitivo y educación. Madrid: Morata.

- Cela Conde, C. J. \& Ayala, F. J. (2001). Senderos de la evolución humana. Madrid: Alianza Editorial.

- Chomsky, N. (2003). La (des)educación. Barcelona: Crítica.

- Erikson, F. (1993). El discurso en el aula como improvisación. En Velasco Maíllo, H.M., García Castaño, F.J. y Díaz Rada, A. (Eds.). Lecturas de Antropología para educadores. Madrid: Trotta. Pp. 325-353.

- Freire, P. (1983). Pedagogía del oprimido. Madrid: Siglo XXI de España Editores, S.A.

- Freire, P. (1999). Pedadogía de la esperanza. México: Siglo XXI Editores.

- Gimeno Sacristán, J. (2002). Hacerse cargo de la heterogeneidad. Cuadernos de Pedagogía, 311, 52-55

- Marquina Espinosa, A. (2004). El ayer y el hoy: Lecturas de antropología política. Madrid: Universidad Nacional de Educación a Distancia, Volumen II. 
- Moreno, I. (2004). Globalización, mercado, cultura e identidad. En Moreno Feliu, P.(comp.). Entre las Gracias y el Molino Satánico. Lecturas de antropología económica. Madrid: UNED. Pp. 485-514.

- Moreno Feliu, P. (comp.) (2004). Entre las Gracias y el Molino Satánico. Lecturas de antropología económica. Madrid: Universidad Nacional de Educación a Distancia.

- Ortega y Gasset, J. (1955). Ideas y creencias. Madrid: Espasa Calpe.

- Ortega y Gasset, J. (2004). Obras Completas, Tomo I. Madrid: Taurus.

- Pérez Gómez, A. (1998). La cultura escolar en la sociedad neoliberal. Madrid: Morata.

- Ramírez Goicoechea, E. (2005). Evolución, cultura y complejidad. La humanidad que se hace a sí misma. Madrid: Centro de Estudios Ramón Areces.
- Sánchez Corral, L. (2004). De la crisis de la significación o las palabras pervertidas. Lección inaugural del curso 2004-2005. Universidad de Córdoba, Córdoba.

- Sennet, R. (2000). La corrosión del carácter. Barcelona: Anagrama.

- Tedesco, J. C. (1995). El nuevo pacto educativo. Educación, competitividad y ciudadanía en la sociedad moderna. Madrid: Grupo Anaya, S.A.

- Urciolli, B. (2004). Una diferencia aceptable: La evolución cultural del ciudadano étnico modelo en EE. UU.En Maquina Espinosa, A. (ed.). El ayer y el hoy: Lecturas de antropología política. Volumen II Madrid: Universidad Nacional de Educación a Distancia. Pp. 105-126. 